\title{
REALISMO E ANTI-REALISMO NA CIÊNCIA: ASPECTOS INTRODUTÓRIOS DE UMA DISCUSSÃO SOBRE A NAT UREZA DAS TEORIAS
}

M arcos Rodrigues da Silva*

Resumo: Este artigo apresenta, de forma sistemática, a discussão entre realismo e anti-realismo na ciência, tendo como objetivos principais a reconstrução e a crítica de ambas teorias.

Unitermos: Realismo científico; verdade.

Abstract: This paper brings forward, in a systematic way, the discussion about realism and anti-realism in science, having as main aims, the reconstruction and the criticism of both proposals.

Keywords: Scientific realism; truth.

\section{APRESENTAÇÃO DAS POSIÇÕES REALISTA E ANTI-REALISTA NA CIÊNCIA.}

U ma caracterização bastante comum para a afirmação do realismo científico se coloca na seguinte tese: as teorias científicas possuem um valor-deverdade (o verdadeiro ou o falso), uma vez que os enunciados teóricos referem a entidades externas à teoria, sendo que estas entidades realmente existem. 0 realista mostra-se comprometido com entidades inobserváveis (externas à teoria, e, principalmente, descobertas pela teoria), e alega que este compromisso decorre de uma tentativa de explicação da ciência (e, em alguns casos, de outras modal idades cognitivas) que se apresenta como mais bem-sucedida do que as alternativas disponíveis, pois a vantagem de sua concepção reside no fato de que ele possui um critério externo para a avaliação do conhecimento. $E$, somente por isto, podemos ainda fazer al guma menção à verdade. Esta, por sua vez, seria a correspondência das nossas proposições com o mundo - uma proposição é verdadeira quando ela afirma o que realmente ocorre no mundo, caso contrário, ela é falsa. 0 mundo externo, portanto, se estabelece como o tribunal das proposições (e das teorias). (Entenda-se porém, que mundo aqui não significa apenas o mundo externo observável, mas também um mundo constituído por entidades inobserváveis.)

Para o realista, o mundo é considerado, sob o ponto de vista ontológico, como constituído por propriedades autônomas. Assim, o mundo externo, num sentido nada trivial considerando que há aqui uma fonte considerável de debate entre as posições realista e antirealista -, seria independente das teorias científicas. Percebe-se, desta forma, a reivindicação básica do realismo científico: as leis científicas são descobertas, ao contrário da posição antirealista, que as postula como invenções (cf. van Fraassen 1989:7).

$\mathrm{Na}$ perspectiva realista, as entidades teóricas existem (autonomamente); assim, elas são descobertas, e figuram como constituintes teóricos das explicações científicas. Um bom exemplo disto se encontra na mecânica newtoniana, onde as definições das entidades teóricas

\footnotetext{
* Professor Assistente do Departamento de Filosofia da Universidade Estadual de Londrina - PR. (email: marcoss@@npd.uel.br)
} 
ali presentes tornam claro 0 caráter independente destas entidades com relação à teoria que está veiculando-as. Força, inércia, gravidade, não são constructos mentais, mas entidades realmente existentes, pois elas revelam a estrutura causal do mundo, e permitem uma explicação em torno destes mecanismos causais. Como veremos adiante, exatamente neste ponto incidiu a crítica anti-realista. Um dos adversários mais brilhantes de N ewton, George Berkeley, recusou-se a aceitar as conseqüências realistas de sua mecânica, uma vez que estas não poderiam ser observadas diretamente por intermédio dos sentidos. Ao invés disso, Berkeley as entendia como criações teóricas, sem nenhuma referência externa: força, inércia e gravidade são categorias explicativas, e não possuem autonomia ontológica. Elas acomodam, de uma forma bastante razoável, o material da experiência; não obstante, elas não referem a entidades extrateóricas. A gravidade seria apenas uma forma de expressar um tipo de relação entre os corpos - em suma, a gravidade é uma entidade teórica, concebida e, além disso, extremamente bemsucedida para dar conta de uma explicação (cf. M atthews 1994:169)1. Ao contrário, para $\mathrm{N}$ ewton, ela subsiste nos corpos, e coube à ciência descobri-la.

Ao contrário do realista, o anti-realista não julga como necessário o comprometimento com entidades sob o ponto de vista ontológico. N ossas hipóteses acerca do mundo são apenas construções mentais, que se impõem não por seu caráter referencial, mas em função de sua capacidade explicativa. A existência é um predicado atribuído a coisas (particulares); a universalidade é uma construção lingüística, que acomoda o material da experiência e torna a ciência possível. M as, uma vez que abandonamos a perspectiva realista, e percebemos que 0 que existe é apenas o particular -, ou nos tornamos céticos ou aceitamos que o que nos resta são as experiências sensoriais particulares. Entretanto, 0 anti-realista sabe que a experiência não pode legitimar a ciência, e, por isso, apela a um tipo especial de vocabulário que possa ser compartilhado pela comunidade científica. 0 corre, que disto não se segue um apelo à verdade; a finalidade das teorias não é a verdade, mas apenas uma acomodação das nossas crenças a al gum quadro teórico aceitável, de modo que elas possuam al guma utilidade epistêmica.

A discussão entre realismo e anti-real ismo acerca da ciência e da metaciência poderia ser entendida a partir de um ponto que é central para a assunção de uma outra atitude intel ectual: o estatuto dos objetos estudados pela ciência. Para o realista², os objetos da ciência são reais, e existem independentemente dos sistemas subjetivamente estruturados a fim de prover adequada sustentação para nossas crenças; nesta perspectiva, o mundo é composto de entidades parcialmente autônomas, e a epistemologia opera sem um sujeito conhecedor (cf. Popper 1972:107): 0 crescimento do conhecimento significa o progresso das teorias em direção à verdade, e este progresso independe do estado de nossas crenças sobre o mundo. $\mathrm{Na}$ visão realista, o mundo precede a mente (e, naturalmente, as teorias por ela produzidas), de modo que esta se adapta ao caráter objetivo daquele. Além disso, admite-se que a mente nem

\footnotetext{
1 Percebese aqui que a principal reivindicação realista - a verdade como correspondência aos fatos - é abandonada. $\mathrm{N}$ ão possuímos a capacidade (e devemos renunciar à possibilidade) de acessar o mundo como ele é em si mesmo, portanto, a postura correta é aquela que se pauta em função da impossibilidade epistêmica da corre spondência dos enunciados teóricos com entidades extra-teóricas. M atthews cita exemplarmente Glasersfeld:“0 fato de que o conhecimento científico nos capacita enfrentar [o mundo], não justifica a crença de que o conhecimento científico forneça um quadro do mundo que corresponde a uma realidade absoluta" (M atthews 1994:140). $M$ ichael $M$ atthews é um dos pensadores atuais que procuram vincular a discussão epistemológica à questão do ensino de ciências. U ma discussão mais detalhada sobre M atthews pode ser vista em Silva (1997). Além disso, conferir 0 artigo do professor Eduardo Barra - publicado neste volume -, que discute a questão da realidade do mundo científico. 2 Conforme Plastino (1995, p. 9), o realismo científico se caracteriza como um conjunto de teses, das quais destacamos a que afirma a independência (também parcial, num certo sentido) do mundo em relação às nossas teorias. São elas: "1) A existência e a natureza dos fatos do mundo não dependem das teorias ou métodos que a
} 
sempre capta 'o que realmente há' no mundo, o que significa afirmar, dentro de uma perspectiva realista 'adaptativa' conjectural (cf. Churchland 1985:45) que nossas teorias são ape nas hipóteses que possuem um valor na luta pela sobrevivência dos organismos. Via de regra, o realista admite a existência de um padrão extra-teórico para o julgamento dos produtos científicos. Assim, as teorias não apenas descrevem aparências, mas atribuem estatuto ontológico a estados de coisas - as teorias referem. A estrutura do mundo é descrita (hipoteticamente) pelas teorias, e é esta estrutura (objetiva) que permite a demonstração de que determinados sistemas teóricos são verdadeiros e que outros são falsos.

0 anti-realista, como vimos, nega 0 estatuto ontológico dos objetos científicos; assim, tais objetos são constructos mentais que nos permitem o controle da natureza. Ele possui dois argumentos contra o realismo, sendo o primeiro deles um argumento ontológico, e o segundo, de ordem metodológica. 0 argumento ontológico diz respeito à possibilidade de acesso epistêmico ao mundo, e teve sua formulação bastante desenvolvida pelo filósofos re presentantes do empirismo inglês. Como sabemos, para um empirista, o conhecimento restringe-se aos dados sensíveis (percepções); mas estes dados revelam apenas fenômenos observáveis, e não sua estrutura subjacente. Portanto, quando afirmamos que uma determinada causa é a origem de um efeito, procedemos filosoficamente de forma ilegítima, uma vez que possuímos acesso apenas aos efeitos (observáveis); a passagem dos efeitos (observáveis) às causas (inobserváveis) será estatuída ou por razões metodológicas estritamente empiristas (Locke), ou por razões de ordem moral (H ume), mas isto não significa afirmar que nossas teorias se deparam com a estrutura causal do mundo. Além disso, o realista, ao não fornecer a resposta para a questão ontológica levantada pelo empirismo, compromete-se de forma constrangedora com o idealismo (cf. Rorty 1994:299), pois a possibilidade de acesso epistêmico sustentada pelo realista poderia ser entendida, muito justamente, como um apelo platônico de identificação entre a mente e o mundo.

0 argumento metodológico contra o realismo se encontra na tese da subdeterminação das teorias pelos dados. Esta tese sustenta que "para cada questão existiria sempre um par de teorias [empiricamente] equival entes que são logicamente imcompatíveis" (cf. N ewtonSmith 1985:156). Assim, as evidências empíricas que corroboram uma teoria são aduzidas como evidências para a corroboração de uma outra teoria rival, o que significa dizer que 0 mundo externo não pode fornecer um padrão externo de conformidade das teorias. Como colocou Berkeley (cf. N ewton-Smith 1985:157), as forças atribuídas aos corpos não passam de hipóteses matemáticas, e como as entidades matemáticas não são reais, uma outra explicação alternativa seria ainda possível: 'a mesma coisa pode ser explicada de modos diferentes'. Percebe-se aqui uma implosão da idéia de verdade, considerando a ausência de um padrão externo para a atribuição de tal predicado às teorias.

Pois bem, cabe ao filósofo que sustenta a tese da subdeterminação demonstrar a existência de alternativas teóricas equivalentes sob o ponto de vista da evidência empírica. Contudo, além desta demonstração ser altamente problemática sob o ponto de vista histórico (cf. Plastino 1995:34), o anti-realista estaria a incorrer no mesmo erro por ele apontado na

ciência utiliza. 2) Toda asserção científica, interpretada literalmente, é ou verdadeira ou falsa. 3) 0 valor-de-verdade de uma asserção científica é determinado pelo mundo. Uma asserção é verdadeira quando mantém uma relação de correspondência com o mundo. 4) A ciência procura teorias que façam uma descrição verdadeira (ou aproximadamente verdadeira) do mundo. 5) Os termos teóricos preservam sua referência durante as mudanças científicas. As teorias científicas sucessoras incorporam o cerne das teorias precedentes. 6) 0 progresso da ciência consiste num progresso convergente de aproximação de uma teoria científica completa e verdadeira. 7) $\mathrm{N}$ as ciências maduras, as teorias são aproximadamente verdadeiras e seus termos centrais referem-se a objetos do mundo." 
estratégia realista: somente aquele que conseguisse extrair da experiência a evidência necessária para a confirmação de uma teoria (e, no caso do defensor da tese da subdeterminação, a evidência para o apoio de uma teoria rival) poderia afirmar que duas (ou mais) teorias são subdeterminadas pela experiência. M as, sendo assim, tornaríamos a cair no problema ontológico.

\section{CONSIDERAÇÕES CRÍTICAS SOBRE O REALISMO E 0 ANTI-REALISMO.}

Parecenos que o problema central da pugna entre realismo e anti-realismo reside na atribuição do caráter evolutivo da ciência - como explicar o sucesso da ciência? Colocando a questão deste modo, pareceria, de início, que a explicação realista seria mais razoável do que a proposta pelo instrumentalismo. A razão disto é bastante simples. A tese da subdeterminação não leva em conta o próprio avanço da ciência, uma vez que as evidências empíricas podem variar de acordo com o progresso das teorias. (N este caso, as evidências empíricas que, num determinado momento confirmam a tese da subdeterminação, poderiam ser revistas por uma nova teoria.) Assim, o realismo estaria mais próximo de uma reconstrução racional do progresso científico do que a posição rival. Contudo, esta explicação não é ainda suficiente, considerando que o realismo explica o progresso da ciência a partir de seu êxito prático, para daí então derivar a possibilidade de uma metodologia realista. $\mathrm{M}$ as, como assinalou van Fraassen (1989:10,88), o êxito de uma teoria não implica na verdade da teoria, mas no preenchimento de alguns requisitos básicos para sua aceitação, que poderiam ser chamados de virtudes: "D e acordo com o realista, quando alguém propõe uma teoria, ele está afirmando-a como verdadeira. M as de acordo com o anti-realista, o proponente não afirma que a teoria é verdadeira; ela apresenta-a, e reivindica certas virtudes para ela." (van Fraassen 1989:10)

U ma outra razão pela qual o realismo é insuficiente como explicação metacientífica é o fato de que ele padece da mesma enfermidade do anti-realismo, sob o ponto de vista do progresso da ciência. 0 realista, afirma Putnam (1992:83) se vê em apuros quando de sua avaliação - sob o ponto de vista do valor-de-verdade - de enunciados como "a terra é plana". H á 3.000 anos ela era verdadeiro ou falso? O ra, se respondermos com base em nosso conhe cimento atual, podemos dizer que ele era fal so, pois a terra não era plana. $\mathrm{N}$ ão obstante, coloca Putnam, este enunciado, há 3.000 anos, fazia parte um corpo razoavelmente ordenado de crenças, e era, portanto, 'racionalmente aceitável'.

0 enunciado 'A Terra é plana' era, muito provavelmente, racionalmente aceitável há 3.000 anos; mas não é racionalmente aceitável hoje. No entanto seria errado dizer que 'a Terra é plana' era verdadeiro há 3.000 anos; porque isto significaria que a Terra tinha mudado de forma. (Putnam 1992:83-84)

De acordo com Laudan (1996:125-126), estamos diante de um problema metametodológico: como justificar a aceitabilidade de um ou outro programa metodológico? Para ele, a epistemologia deixou-se vencer pelo requerimento da 'reconstrução racional' dos episódios científicos, o que ocasionou uma grande guinada em direção ao relativismo. A proposta de Laudan, é de queé possível a escolha entre uma ou outra metodologia, sem no entanto comprometer-se com o requerimento acima colocado. A razão disto, é que os episódios

"N as ciências maduras, as teorias são aproximadamente verdadeiras e seus termos centrais referem-se a objetos do mundo." 
históricos revelam invariavelmente violações das regras metodológicas propostas (Laudan 1996:128); entretanto, disto não se segue uma conclusão sobre a insignificância das regras metodológicas (Kuhn 1970:42), ou mesmo de uma equivalência entre as metodologias (Feyerabend 1989:34). Para Laudan, uma metodologia poderia ser preferida à outra na medida em que ela considerasse os agentes envolvidos nos episódios científicos pretéritos menos como agentes racionais do que como cientistas que agiam em função de fins cognitivos pré estabelecidos (e que dirigiam sua atenção para a concretização destes fins). Assim, tanto o realismo - que propõe a verdade com um fim cognitivo - quanto 0 anti-realismo - que acredita que o objetivo da ciência é salvar as aparências - fracassam como alternativas metodológicas, uma vez que os objetivos da ciência não são objetivos gerais (atemporais), mas estão localizados em circunstâncias bastante definidas pelos fins cognitivos (não-gerais) almejados pelos cientistas (cf .Laudan 1996: 130).

Para concluir, gostaria de mencionar um outro ponto de conflito entre realismo e anti-realismo. É bastante comum, nos escritos realistas, a acusação de que a renúncia ao realismo implicaria em al go como o ceticismo. U ma das fontes deste argumento se encontra em $D$ arwin. Em sua teoria da evolução, $D$ arwin sustentou a idéia de que as espécies estão expostas a uma luta constante pela sobrevivência; esta, se efetivaria a partir de um princípio denominado de sel eção natural: uma espécie é sel ecionada, se ela conserva as variações favoráveis à sua sobrevivência e descarta as variações desfavoráveis ( $D$ arwin 1963:64). Se pressupormos, como D arwin, a autonomia da seleção natural - 'ela está, dia a dia, hora a hora, examinando por todo o mundo, cada variação, ainda que mínima, rechaçando o mal, conservando e acumulando tudo 0 que é bom; trabal hando silenciosamente, insensivelmente quando e onde quer que se ofereça a oportunidade, para a melhoria de cada ser orgânico' (cf. D arwin 1963:66) -, operando como uma invisible hand, então pareceria razoável que assumíssemos que não se pode trapacear quando estamos jogando com a natureza. Uma vez que estamos submetidos ao implacável veredicto do tribunal da seleção natural, nossos meios utilizados para os fins da adaptação (ou seja, nossas teorias) devam se conformar aos padrões daquela - num sentido naturalistả, nossas teorias devem ser verdadeiras. D esta forma, nossas teorias não são construções como outra qualquer, mas instâncias legitimadoras de nosso êxito em descobrir regularidades veiculadas pela estrutura causal do mundo. Esta tese é sustentada mesmo por aqueles que, como Churchland, rejeitam a concepção de que a verdade é o objetivo da ciência. Em sua perspectiva adaptativa conjectural do realismo científico, Churchland propõe a existência de algum princípio de correspondência entre as crenças humanas e a natureza, sendo que este princípio seria responsável pelo êxito do organismo em sua luta pela sobrevivência.

Contudo, como nos lembra Ghiselin (1969:57), a abordagem de Darwin com relação à extinção das espécies não levaria em conta apenas a pugna entre espécie e natureza, mas igualmente o duelo entre as próprias espécies. Em outros termos, o triunfo de uma espé cie não significa exatamente o domínio de representações privilegiadas sobre a natureza, mas apenas a posse de uma estratégia adequada se sobrevivência4. Além disso, como coloca Kitcher (1992:92), em uma passagem de inspiração decididamente kuhniana, o cérebro humano, conquanto considerado um produto da evolução, não poderia servir de modelo para sofisticadas investigações metacientíficas acerca da natureza da ciência, pois esta 'competência mínima' na adaptação não nos 'levaria muito adiante no estabelecimento da confiabilidade do processo

\footnotetext{
30 termo 'naturalista', neste contexto, não referese à epistemologia naturalizada.

4 Esta é a tese de Richard D awkins (1979:38-39). É interessante comparar a idéia de D awkins, de que a evolução não significa exatamente uma 'coisa boa', pois, 'nada, na verdade, quer evoluir', com a concepção kuhniana de que o progresso da ciência não significa igualmente uma aproximação à verdade.
} 
histórico do qual as crenças científicas (...) emergiram.' D esta forma, o dilema típico dos realistas - ou o realismo ou o ceticismo, sendo que aqui - como seria de se esperar -, ceticismo significa simplesmente o produto da adoção de uma epistemologia não comprometida com a noção de verdade - pode também ser estendido aos próprios realistas, na seguinte disjunção: ou o instrumentalismo ou o ceticismo. (Isto foi feito, por exemplo, por Berkeley.)

Por fim, gostaria de ressaltar que vejo como promissora a proposta naturalista e 'pragmática' de Churchland, que procura identificar a aceitação de teorias como um processo adaptativo dos organismos. D esta forma, nossas teorias não seriam, como pensava Berkeley, tão boas quanto quaisquer outras explicações equivalentes (cf. N ewton-Smith 1985:157); entre tanto, isto não significaria que elas se identificassem com a verdade, pois 'a seleção natural não está preocupada se um cérebro tende a crenças verdadeiras, contanto que o organismo exiba, de forma confiável, um comportamento reprodutivamente vantajoso'. (C hurchland 1985:45). Assim, parece-me que $C$ hurchland adiantou um interessante argumento contra a idéia de que o realismo seria a pedra de toque contra uma filosofia cética.

\section{Referências Bibliográficas}

BARRA, E. S .O . (1998) A Realidade do M undo da Ciência (publicado neste volume). Churchland, P. (1985) The O ntological Status of O bservables: In Praise of the Superempirical Virtues in Images of Science (ed. Churchland, P. \& H ooker, C.). Chicago: Chicago Press.

DARW IN , C. (1963) The O rigin of Species. N ew York: Washington Square Press.

D AW KIN S, R. (1979) 0 Gene Egoísta. Belo H orizonte: Itatiaia.

FEYERABEN D , P. (1989) Contra o M étodo. Rio de Janeiro: Francisco Alves.

GHISELIN, M . (1969) The Triumph of the Darwinian M ethod. Berkeley: Chicago Press.

KITCHER, P. (1992) The N aturalism Return in The Philosophical Review , v. 101, n. 1

KU H N , T. (1970) The Structure of Scientific Revolutions. Chicago: Chicago Press. LAUDAN, L. (1996) Beyond Positivism and Relativism. Boulder: Westview Press. M ATTHEW S, M . (1994) Science Teaching. N ew York: Routledge.

NEW TON -SM ITH , W.H. (1985) Berkeley's Philosophy of Science in Essays on Berkeley (ed. Foster, J. \& Robinson, H.). Oxford: Clarendon Press.

PLASTIN O, C. (1995) Realismo e Anti-Realismo acerca da Ciência: Considerações Filosóficas sobre o Valor Cognitivo da Ciência. São Paulo: Tese (D outorado), U SP. PO PPER, K.R . (1972) O bjective Knowledge. O xford: Claredon Press. 
PUT N AM , H . (1992) Razão, Verdade e H istória. Lisboa: D om Q uixote. RORTY, R. (1994) Philosophy and the M irror of Nature. Oxford: Blackwell. SILVA, MARCOS RODRIGUES (1997) Michael Matthews e os Compromissos Epistemológicos e 0 ntológicos do Construtivismo in Educação eRealidadev. 22, n.2.

VAN FRAASSEN , B. (1989) The Scientific Image. O xford: Clarendon Press. 